\section{From patient advocate to gatekeeper: understanding the effects of the NHS reforms}

I read Clare Gerada's article in the BJGP November issue ${ }^{1}$ with some surprise. I had to read to her last paragraph to find areas of agreement with her. I do believe that continuity, accessibility, caring, and the coordination of this matter to patients.

I do not believe the current NHS achieves this well. There are many breaks in continuity throughout the system: within GP surgeries; between GPs and other primary healthcare team members; between GPs and secondary care services; and between health and social care. Access to care is reasonable, but it could be better. Coordination of care could be better at all levels across the NHS. Why are patients sent home from hospital wondering when their outpatient appointment or follow-up test is booked for? Why are they seeing GPs in the vain hope that we will have any better information than they have? Why are they spending time and running up costs, in the wrong part of the system, at the wrong time, for the wrong reason? Why do we expect our fellow citizens to pay taxes for us to indulge such inefficiency? The current UK NHS is a moderately successful health service, but it is in need of improvement. The NHS has been described by Nigel Lawson as, 'the closest thing the English have to a religion.' Rabbi Julia Neuberger commented that she thought its priests had lost faith in their religion. ${ }^{2}$ Practically the NHS needs to be justified by its works, not by faith.

As doctors we need to own the fact that care costs. ${ }^{3}$ Fragmentation is inefficient, and wastes time and money. ${ }^{4}$ Every decision we make is both clinical and financial. Every statement we make about the worth or value of any treatment is, in part, a financial evaluation. Every decision we make incurs a cost that the NHS is paying. Every pound can only be spent once, so every decision to do one thing is by default simultaneously a decision not to do another. To a large extent NHS doctors have been insulated from the financial consequences of their actions, and the NHS as a whole has borne them. As Tudor Hart describes, 'at one stage no one in the NHS had much or any idea about how much anything cost'. In the modern era we cannot get away with such laxity, and indeed in secondary care the accuracy of the coding for payment by results is improving meaning that we now have a far clearer idea about what they are doing, and the levels of comorbidity they are dealing with. Perhaps such techniques need to be extended to primary care so that we get more finely grained information about what and how much we actually do, and then we can stop regretting how much primary care works goes unmeasured, unappreciated, and unpaid.

In other industries workers at a similar level of seniority to GPs would be expected to be accountable for the simultaneous flows of activity and money. Commissioning challenges us to do this for the NHS. It is not a challenge we will all like, but I think it is one we cannot honourably decline.

As I see it, commissioning is the chance our generation of doctors will have to make the NHS navigable. ${ }^{6}$ It is not about either 'gatekeeping' or 'advocacy'. It is not about anything American at all. It is about making the NHS in England work better for its patients.

Far from commissioning heralding the end of the NHS, I see it as the opportunity we have to get the NHS right for the generation to come.

\section{Peter Davies,}

FRCGP, GP, Keighley Road Surgery Illingworth, Halifax, HX2 9LL; Member, Calderdale Clinical Commissioning Group. E-mail: md014j1265ablueyonder.co.uk

\section{REFERENCES}

1. Gerada C. From patient advocate to gatekeeper: understanding the effects of the NHS reforms. $\mathrm{Br} J$ Gen Pract 2011; 61(592): 655-656.

2. Neuberger J. The NHS as a theological institution. The ideal remains strong, but the practice too has to measure up. BMJ 1999; 319(7225): 1588-1589.

3. Garbutt G, Davies P. Should the practice of medicine be a deontological or utilitarian enterprise? J Med Ethics 2011; 37(5): 267-270.

4. Seddon J. Systems thinking in the public sector: the failure of the reform regime ... and a manifesto for a better way. Axminster: Triarchy Press, 2008.

5. Tudor Hart JT. A new kind of doctor. London: Merlin Press, 1988.
6. The King's Fund. Improving the quality of care in general practice. Independent inquiry into the quality of care in general practice in England. London: The King's Fund, 2011.

http://www.kingsfund.org.uk/publications/gp_inquir y_report.html laccessed 29 Nov 2011).

DOI: 10.3399/bjgp12X616247

In her editorial the Chair of the Royal College of General Practitioners describes the role of GPs as gatekeepers in a negative light.' She asserts that this role has arisen in the past 20 years as a result of GPs being encouraged to take financial, as well as clinical, responsibility for their patients. In fact the role of the GP as a gatekeeper has been recognised for at least the past 100 years. ${ }^{2}$ There should be nothing demeaning about GPs having a gatekeeper role - it has been associated with the cost-effective delivery of healthcare services the world over. ${ }^{3}$

The role of advocate, that she proposes, has legal rather than medical roots. The advocate's only duty is to their client. It presupposes the separate and distinct role of a judge who is responsible for final arbitration. Such separation of advocacy from decision-making is a luxury that does not exist in medicine. In seeking to disengage GPs from the financial concerns of providing health care Dr Gerada is not helping us face reality. It may help us to see financial resources as we do any other finite resource, for example, a blood bank or a doctor's time. Clinical triage principles would direct a doctor to use the blood supplies on those patients in whom it would gain the greatest benefit and not those for whom its use would be marginal or futile. Similarly, a doctor does not decide how to allocate their time simply on the basis of one patient's need but has to spend it with regard to all their patients' needs. In both these cases the doctor does not behave as an advocate for an individual patient but as a steward (a gatekeeper even) of a finite resource who seeks to maximise its effectiveness. It is also important to be clear that the GP would be at fault for closing the gate unnecessarily as well as for opening it irresponsibly. Therein lies the complexity and value of general practice.

\section{John Matthews,}

GP, Park Road Medical Practice, Wallsend, NE28 7LP; Chair, CareFirst Pathfinder Care 